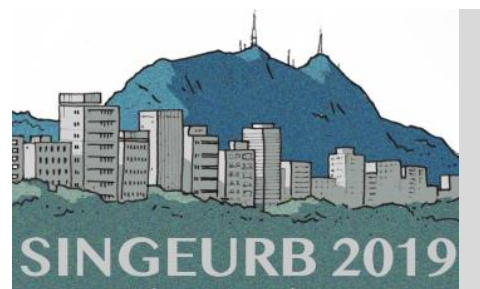

II Simpósio Nacional de Gestão e Engenharia Urbana

ABORDAGEM SISTÊMICA, ESCALAS E INTERSETORIALIDADE:

DESAFIOS E POTENCIAIS DO DESENVOLVIMENTO URBANO SUSTENTÁVEL

27 a 29 de novembro-USP

\title{
Uso do modelo Freturb na análise das interdependências entre aspectos do transporte urbano de carga e do planejamento urbano em uma região central do município de São Paulo'
}

\section{Use of the Freturb model in the analysis of the interdependencies between aspects of urban freight transport and urban planning in a central region of the municipality of São Paulo}

\author{
Montmorency Silva, Thiago Canhos'; Marins, Karin Regina de Castro² \\ 1 Escola Politécnica da Universidade de São Paulo, Av. Prof. Almeida Prado, \\ trav.2 n. 83 - Edifício Paula Souza (Prédio da Engenharia Civil), Brasil, \\ thiagocanhos@gmail.com \\ 2 Escola Politécnica da Universidade de São Paulo, karin.marins@usp.br
}

\begin{abstract}
RESUMO
O trato da carga urbana ainda é incipiente no planejamento integrado das cidades brasileiras. O objetivo deste trabalho é analisar aspectos do transporte urbano de carga e parâmetros do planejamento urbano por meio da aplicação do modelo Freturb em uma área urbana, localizada na região central do município de São Paulo. Freturb estima o número de veículos atraídos por uma área urbana, em função dos tipos, tamanhos e das densidades dos estabelecimentos comerciais instalados, em função das suas necessidades logísticas. Seus resultados possibilitam caracterizar a geração dos movimentos da carga urbana e seus impactos em uma área urbana. Dentre as principais inter-relações identificadas, destacamse os respectivos resultados: a relação das densidades de empregos com a de movimentações de carga; a correlação do perfil econômico do estabelecimento com o tempo da operação de carga/descarga; a relação entre a diversidade das densidades de movimentações de carga e os diferentes setores econômicos da cidade. Espera-se, com este trabalho, contribuir, em âmbito brasileiro, para o desenvolvimento de instrumentação e parametrização integradas e intersetoriais, neste caso, com especial atenção ao transporte urbano de carga com as políticas de uso e ocupação do solo no município de São Paulo.
\end{abstract}

Palavras-chave: transporte urbano de carga, uso e ocupação do solo, densidades urbanas, modelagem urbana, Freturb.

\footnotetext{
ABSTRACT

The treatment of the urban freight is still incipient in the integrated planning of Brazilian cities. The objective of this work is to analyze aspects of urban freight transport and urban planning parameters by applying the Freturb model in an urban area, located in the central region of the city of São Paulo. Freturb estimates the number of vehicles attracted by an urban area, depending on the types, sizes and densities of the commercial enterprise installed, depending

${ }^{1}$ MONTMORENCY SILVA, Thiago Canhos; MARINS, Karin Regina de Castro. Uso do modelo Freturb na análise das interdependências entre aspectos do transporte urbano de carga e do planejamento urbano em uma região central do município de São Paulo. In: II SIMPÓSIO NACIONAL DE GESTÃO E ENGENHARIA URBANA: SINGEURB, 2019, São Paulo. Anais... Porto Alegre: ANTAC, 2019.
} 
on their logistical needs. Their results make it possible to characterize the generation of urban freight movements and their impacts in an urban area. Among these inter-relationships, the results are: the ratio of the densities of jobs with urban freight movements; the correlation of the economic profile of the enterprise with the time of the loading/unloading operations; the relationship between the diversity of the densities of freight movements and the different economic sectors of the city. The aim of this work is to contribute, in the Brazilian context, to the development of integrated and inter-sectoral instrumentation and parameterization, in this case, with special attention to the urban freight transport with the land use policies in the city of São Paulo.

Keywords: urban freight transport, land use, urban densities, urban modeling, Freturb.

\section{INTRODUÇÃO E OBJETIVOS}

Há uma predisposição crescente do adensamento populacional nas cidades, por meio do Uso misto (MARINS e ROMERO, 2012; SILVA e MARINS, 2014; DABLANC e FRÉMONT, 2015; MONTMORENCY SILVA e MARINS, 2019). O rápido desenvolvimento da urbanização, associado à sua vitalidade econômica, incrementam as grandes movimentações de mercadorias nas cidades, que, também, são relacionados aos novos padrões de produção/consumo da população. Os impactos destas movimentações de mercadorias são, ainda, poucos estudados e superficialmente abordados em políticas públicas e projetos urbanos. Isto posto, há a tendência, portanto, de degradação na qualidade de vida urbana e desestruturação da dinâmica socioeconômica das cidades (DABLANC e FRÉMONT, 2015; MONTMORENCY SILVA E MARINS, 2019).

No Brasil, o planejamento e a gestão de cidades carecem do uso de modelos de avaliação integrada envolvendo o transporte urbano de carga e os parâmetros urbanísticos de uso e ocupação do solo. Routhier e Toilier (2007) e Montmorency Silva e Marins (2019) apontam benefícios ao utilizar ferramentas de simulação no apoio ao planejamento, à otimização e à gestão da carga urbana.

O modelo Freturb foi desenvolvido pelo Laboratoire Aménagement Economie Transports da Universidade de Lyon (LAET-UdL), na França, para apoiar administrações municipais francesas e tem abordagem integrada do planejamento urbano com a logística urbana. Routhier e Toilier (2013) comentam que o objetivo do Freturb é avaliar cenários do transporte de carga numa área urbana. Sua função é estimar o número de veículos atraídos por uma área urbana, em função dos tipos, tamanhos e das densidades dos estabelecimentos comerciais instalados, em função das suas necessidades logísticas. Já a aplicabilidade do modelo está relacionada com a possibilidade de caracterizar, com seus resultados, a geração e os impactos dos movimentos da carga numa área urbana.

A fundamentação dos elementos constituintes do Freturb, seus procedimentos e a análise de seu detalhamento matemático foram realizados a partir do levantamento bibliográfico que estão expostos por Routhier e Toilier (2007), Delaître e Routhier (2010), Ambrosini et al. (2013) e Beziat (2013). Já a sua adaptação, metodologia de aplicação e verificação de seus resultados, numa área urbana central de São Paulo, estão apresentados em Montmorency Silva e Marins (2019).

Para a simulação no Freturb, são necessários dois arquivos de entrada:

- O "Zona Urbana", que abrange as características geográficas e densidades urbanas do local, e neste caso foram utilizados dados populacionais do Censo Demográfico (IBGE, 2010) e os dados oficiais da Secretaria Municipal de Urbanismo e Licenciamento da Prefeitura de São Paulo (São Paulo, 2019);

- O SIRENE, que contém a base de dados estatísticos e econômicos dos estabelecimentos em uma área urbana francesa, gerido pelo Instituto Nacional de Estatísticas e Estudos Econômicos (INSEE), na França. Para este estudo foi construído um SIRENE próprio, com o apoio do LAET-UdL, a partir dos dados da Relação Anual de Informações Sociais (RAIS), de 2015, do Ministério da Economia. 
Este trabalho tem como objetivo analisar, numa área central da cidade de São Paulo, as interdependências entre aspectos do transporte de carga e do planejamento urbano, por meio da aplicação do Freturb. Constatou-se que estas duas disciplinas se inter-relacionam e há reciprocidade na realidade urbana. E, por fim, verificando que certas inter-relações - tais como: a relação das densidades de empregos com a de movimentações de carga; a correlação do perfil econômico do estabelecimento com o tempo da operação de carga/descarga; como a diversidade das densidades de movimentações de carga, ocasionadas pelos diferentes setores econômicos - são importantes para desenvolver políticas públicas de mobilidade e de planejamento urbano, fomentando a gestão intersetorial nos municípios brasileiros.

\section{A ÁREA URBANA ESTUDADA E SUA ESTRUTURA ECONÔMICA}

A área de estudo, com aproximadamente um quilômetro quadrado, localiza-se numa região central de São Paulo (Figura 1), situada na Subprefeitura da Sé, entre os distritos de Consolação e Santa Cecília, respectivamente com 15.504 e 21.466 habitantes $/ \mathrm{km}^{2}$ (IBGE, 2010). Sua população residente é estimada em 21.803 habitantes, caracterizada por uso misto, alta densidade populacional e importantes ruas e avenidas com comércios/serviços, necessitando, portanto, estudar o comportamento da carga urbana na região. Além de se situar numa zona de influência dos Eixos de Estruturação da Transformação Urbana que, de acordo com o Plano Diretor Estratégico de São Paulo, a área possui incentivos para um possível aumento da densidade populacional e de edifícios com uso misto (SÃO PAULO, 2014).

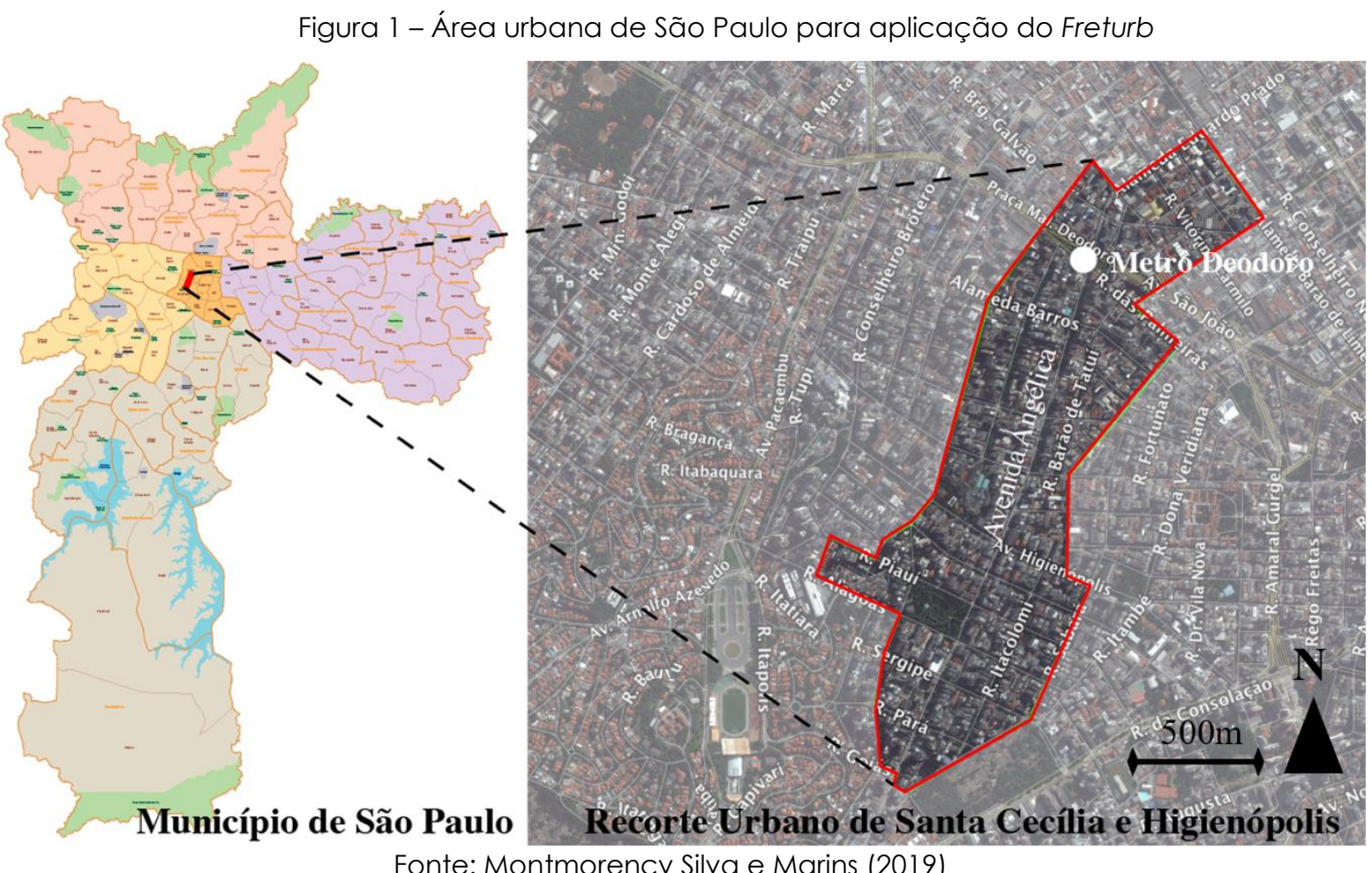

A análise da estrutura econômica da área urbana foi baseada na RAIS de 2015, gerenciada pelo Ministério da Economia do Brasil e obtida em São Paulo (2019), seus dados são apresentados na Tabela 1. A área possui 1.184 estabelecimentos e 23.858 empregos. Verificase que a principal atividade econômica é o setor de serviços/escritórios, com 12.904 empregos (54\% do total) e 223 estabelecimentos (19\%), seguido pelo comércio de varejo, com 5.163 empregos (22\%) e a maior quantidade de estabelecimentos, 392 (33\%). 
Tabela 1 - Quantidades de estabelecimentos e empregos, por setor econômico

\begin{tabular}{ccccc}
\hline Setores Econômicos & Estabelecimentos & $\begin{array}{c}\text { Participação dos } \\
\text { estabelecimentos }\end{array}$ & $\begin{array}{c}\text { Empregos } \\
\text { Agricultura }\end{array}$ & $\begin{array}{c}\text { Participação } \\
\text { dos Empregos }\end{array}$ \\
\hline Serviços manufaturados & 208 & $1 \%$ & 10 & $0 \%$ \\
Indústria & 195 & $18 \%$ & 3.618 & $15 \%$ \\
Comércio de atacado & 102 & $16 \%$ & 1.024 & $4 \%$ \\
Grandes Supermercados & 20 & $9 \%$ & 444 & $2 \%$ \\
Comércio de varejo & 392 & $2 \%$ & 564 & $2 \%$ \\
Serviços/Escritórios & 223 & $33 \%$ & 5.163 & $22 \%$ \\
Armazéns/Depósitos & 35 & $19 \%$ & 12.904 & $54 \%$ \\
\hline Total & $\mathbf{1 . 1 8 4}$ & $3 \%$ & 131 & $1 \%$ \\
\hline
\end{tabular}

Fonte: Adaptado da RAIS de 2015 (SÃO PAULO, 2019)

Na modelagem foi desconsiderado o decreto municipal $n^{\circ} 48.338$, de 10 de maio de 2007, que estabelece restrições, das $9 \mathrm{~h}$ às $21 \mathrm{~h}$, para a circulação de veículos de carga conforme seu tamanho ou peso, por meio da Zona de Máxima Restrição de Circulação. O objetivo é identificar o comportamento das densidades de movimentos de carga em relação as características do uso e ocupação do solo (estabelecimentos), assim, foi desconsiderado o decreto para evitar uma uniformização forçada dos tipos de veículos utilizados no transporte das mercadorias.

\section{RESULTADOS DA APLICAÇÃO DO FRETURB, NA ÁREA EM ANÁLISE}

Os resultados do Freturb mostraram que são gerados 16.577 movimentos $^{2}$ de carga no sistema viário da área de estudo. De maneira geral, $53 \%$ das movimentações utilizaram os VUCs, 35\% por caminhões rígidos ${ }^{3}$ e $12 \%$ por articulados ${ }^{2}$. As distintas relações entre empregos e movimentação da carga, por setor econômico, são observadas na Figura 3; já a heterogeneidade das opções pelos tipos de veículos utilizados no transporte das cargas, quando observados os diferentes setores econômicos, é apresentada na Figura 4.

\footnotetext{
2 Freturb considera "movimento" a soma das viagens de expedição/recebimento da carga pelo estabelecimento.

${ }^{3}$ Freturb classifica os veículos de entrega/coleta em três categorias: (i)Veículo Urbano de Cargas (VUC); (ii)Caminhões Rígidos/Semipesados/Pesados. Os Semipesados possuem eixos simples com rodas duplas na carroceria, comprimento máximo de 14 metros e capacidade de 6 toneladas. Os Pesados têm eixo em tandem na carroceria, com capacidade de 10 a 14 toneladas; (iii)Caminhões Articulados/Extrapesados podem ser engatados com reboques/semirreboques.
} 
Figura 3 - Relação entre empregos e movimentação da carga, por setor econômico

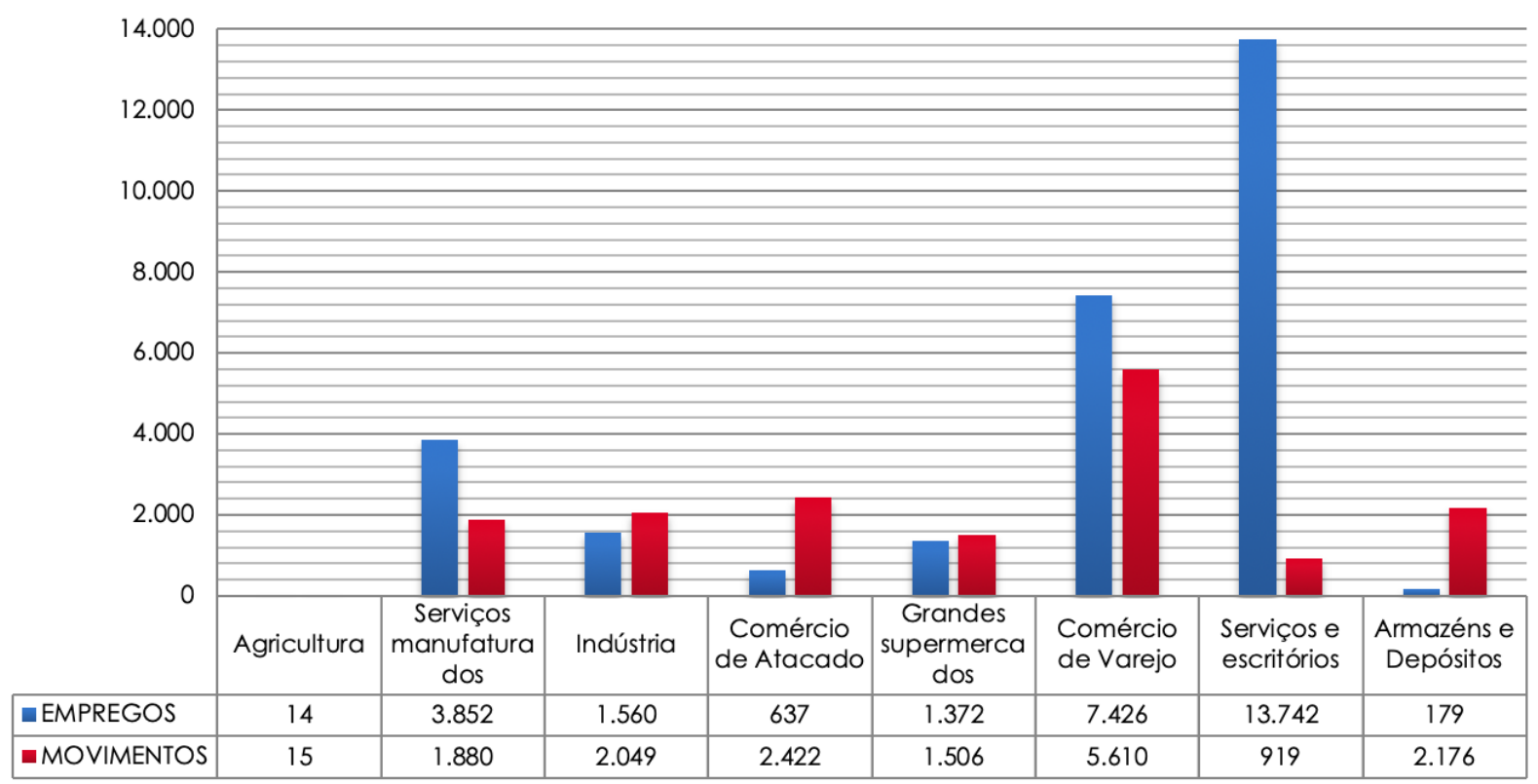

Fonte: Os autores

Figura 4 - Tipos de veículos utilizados na movimentação da carga, por setor econômico

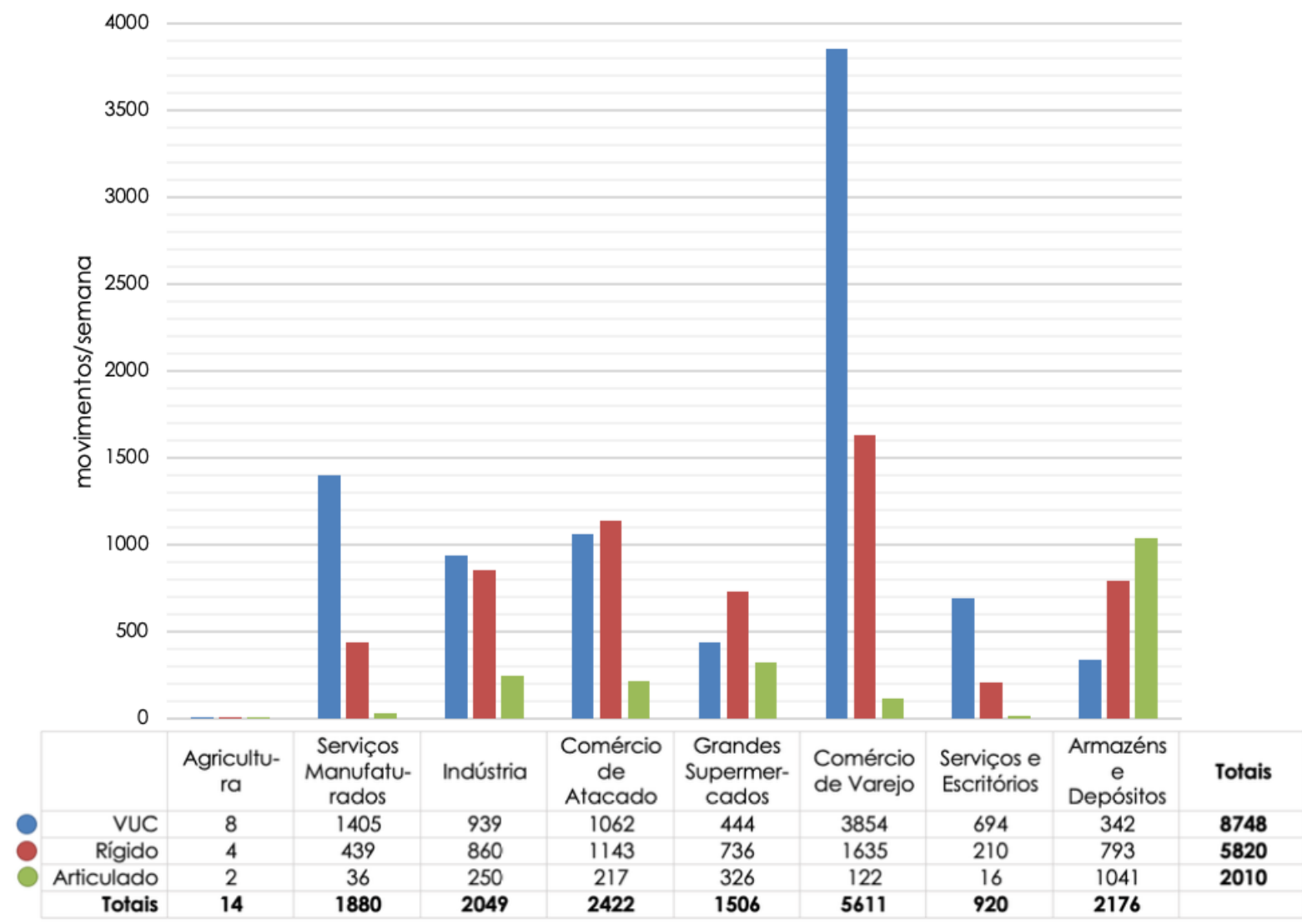

Fonte: Os autores 
Avaliando os resultados dos setores econômicos com maior empregabilidade na área, Serviços/Escritórios e Comércio de Varejo, observam-se os seguintes comportamentos da carga urbana, respectivamente:

- Principal atividade, Serviços/Escritórios contemplam 54\% do total de empregos na área urbana (Tabela 1). Contudo, a movimentação da carga não é representativa, $6 \%$ do total, não ocasionando, dessa forma, grandes impactos no tráfego geral (Figura 3). Em relação aos tipos de veículos utilizados para distribuição das mercadorias, a simulação mostrou que $75 \%$ das movimentações das cargas destes estabelecimentos são realizadas por VUCs. Há, também, uma parte representativa de $23 \%$ das movimentações de mercadorias que utiliza caminhões rígidos. Por fim, os veículos articulados representam apenas $2 \%$ das movimentações das cargas;

- Comércio de Varejo é a segunda atividade econômica em quantidade de empregos e o primeiro em quantidade de estabelecimentos na região. Respectivamente, perfaz $22 \%$ dos empregos (5.163) e totaliza 33\% dos estabelecimentos (392). É a atividade que gera a maior movimentação de carga, são 5.610 movimentos de mercadorias por semana (34\% na região). Logo, a ocupação urbana por esta atividade deve ser avaliada, definitivamente, sob o aspecto do transporte urbano de carga, pois estimular a ocupação do comércio de varejo é aumentar, substancialmente, a movimentação de mercadorias no tráfego em geral. Os resultados do Freturb mostraram que $69 \%$ da movimentação é realizada pelos VUCs, os caminhões rígidos representam $29 \%$ e os articulados, $2 \%$ (Figura 4).

A simulação apontou que são despendidas 6.924 horas por semana (Figura 5) para realizar os abastecimentos/expedições de mercadorias em todos os estabelecimentos. Sendo que, $84 \%$ ocorre em paradas em "fila-dupla"; 9\%, em locais regulamentados; e 7\%, de modo proibido. Estima-se, portanto, que são utilizadas 900 horas por dia, na área urbana, para realizar operações de carga/descarga em desacordo com as normas do código de trânsito vigentes ("fila-dupla"/proibido). Montmorency Silva e Marins (2019) afirmam que estabelecimentos de pequeno porte, predominantes na área, dificilmente ofertam áreas à operação de carga/descarga e, associado à restrição de espaço físico interno em seus estoques, predispõem o reabastecimento frequente em quantidades pequenas. Sendo assim, estabelecimentos de pequeno porte de comércio de varejo exigem mais espaços viários públicos, destinados às operações de carga/descarga.

A distribuição do tempo total de carga/descarga, que os estabelecimentos de cada setor econômico necessitam em suas operações, é mostrada na Figura 5. O setor econômico Armazéns/Depósitos é o que mais necessita de tempo para as operações de carga/descarga na região. Apesar de possuir uma baixa densidade de estabelecimentos, 35 estabelecimentos $/ \mathrm{km}^{2}$ (Tabela 1), o setor é responsável por $24 \%$ do tempo das operações de carga/descarga. Comércio de Atacado é a segunda atividade que demanda uma grande parcela, 17\%, de tempo da operação de carga/descarga. Juntas, Armazéns/Depósitos e Comércio de Atacado, apesar de representarem $12 \%$ dos estabelecimentos na região, por serem atividades de grande porte, necessitam $41 \%$ do tempo das operações. Já Comércio de Varejo, atividade preponderante na área de estudo, é responsável por $21 \%$ do tempo dedicado às operações de carga/descarga. 


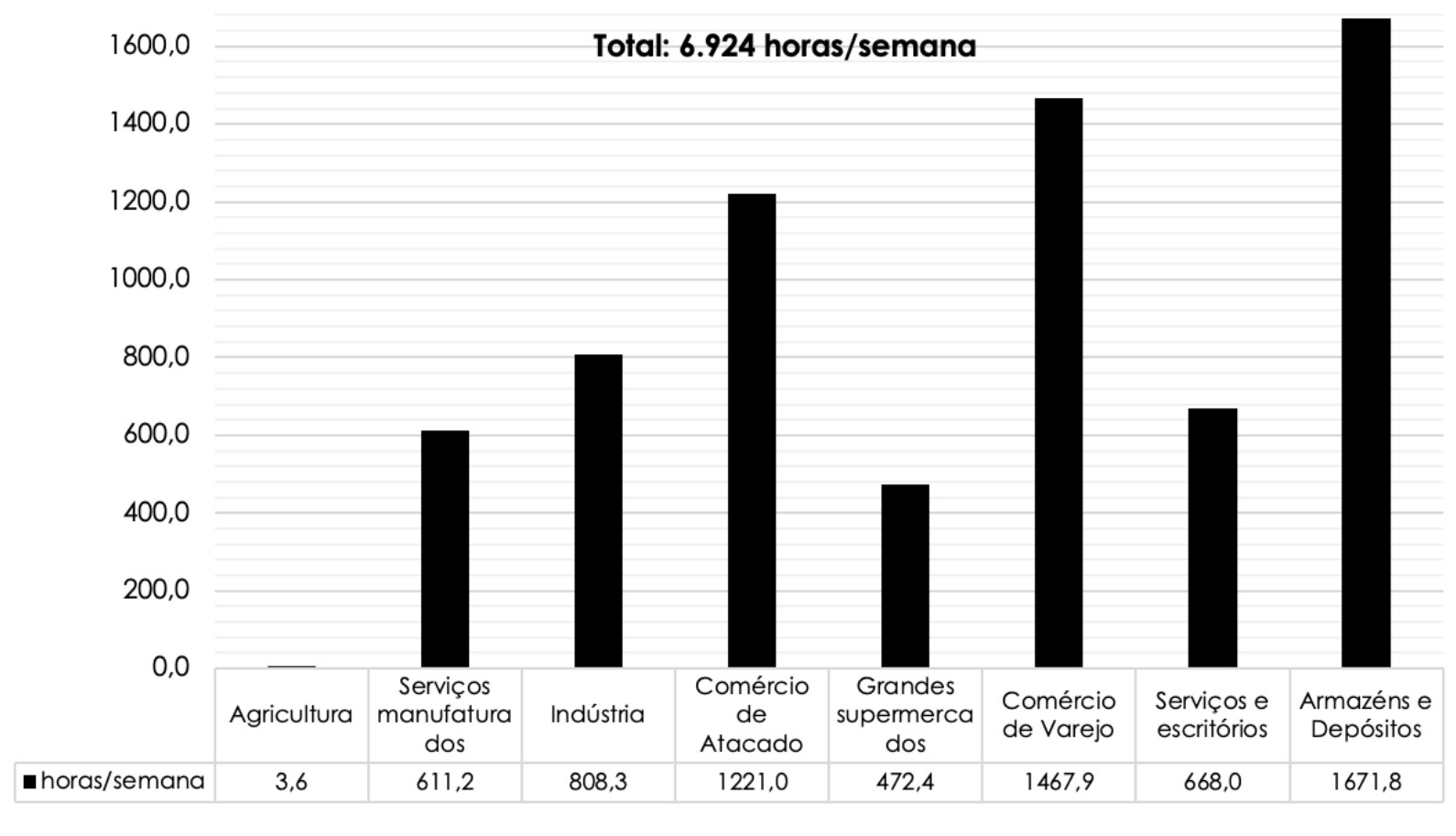

Fonte: Os autores

\section{CONCLUSÕES}

Por meio do estudo de caso, verificou-se que áreas urbanas com alta densidade urbana demandam maior quantidade de mercadorias para esta área, afetando, consequentemente, a capacidade de tráfego viário com o aumento da movimentação dos veículos de carga. Já a alta densidade de movimentos, associada à escassez de espaços urbanos destinados às operações de carga/descarga, sejam públicos ou privados, incrementam as implicações urbanas negativas, dentre elas: os níveis de congestionamentos, ruídos, acidentes e emissões de gases efeito estufa e polventes.

Observou-se que aspectos da carga impactam diretamente no uso do espaço urbano e nas características dos estabelecimentos, como quantidade de empregos e perfil econômico, que podem predispor o aumento de tempo de carga/descarga em uma área urbana. Estabelecimentos de menor porte, por exemplo, demandam transporte de mercadorias em menor quantidade, motivando o transporte de mercadorias com múltiplas paradas para as operações de carga/descarga e, assim, necessitando de mais espaços viários públicos destinados a estas operações.

Constatou-se que parâmetros do uso e ocupação do solo e da logística interagem no meio urbano. E, o entendimento e controle destes parâmetros, por uma gestão urbana intersetorial, devem ser desenvolvidos nos municípios brasileiros, principalmente, quando se incentiva o aumento das densidades urbanas associadas ao uso misto.

\section{AGRADECIMENTOS}

À Coordenação de Aperfeiçoamento de Pessoa de Nível Superior (CAPES), pelo apoio para o desenvolvimento da pesquisa, por meio da concessão de bolsa de estudo.

Ao Laboratoire Aménagement Economie Transports de Université de Lyon (LAET-UdL), pelo suporte obtido em todas as etapas da simulação com o Freturb. 


\section{REFERÊNCIAS}

AMBROSINI, C.; GONZALEZ-FELIU, J.; TOILIER, F. A design methodology for scenario-analysis in urban freight modelling. European Transport, 2013, v. 54, n. 7, p. 1-21.

BEZIAT, A. French cities' urban freight surveys. $1^{\text {st }}$ Scientific and Technical Workshop, Bologna, 2013.

DABLANC, L.; FRÉMONT, A. La métropole logistique. Le transport des marchandises et le territoire des grandes villes. Paris, Armand Colin, 2015, $312 \mathrm{p}$.

DELAÎTRE, L.; ROUTHIER, J. L. Mixing two French tools for delivery areas scheme decision making. Procedia-Social and Behavioral Sciences, 2010, v. 2, n. 3, p. 6274-6285. DOI: 10.1016/j.sbspro.2010.04.037

IBGE - INSTITUTO BRASILEIRO DE GEOGRAFIA E ESTATístICA. Censo Demográfico 2010. Disponível em: <http://www.ibge.gov.br/home/estatistica/populacao/censo2010/>. Acesso em: 21 abr. 2019.

MARINS, K. R. C. C.; ROMERO, M. A. Integração de condicionantes de morfologia urbana no desenvolvimento de metodologia para planejamento energético urbano. Ambiente Construído, Porto Alegre, 2012, v. 12, n. 4, p. 117-137. DOI: 10.1590/S1678-86212012000400009

MONTMORENCY SILVA, T. C.; MARINS, K. R. C. Avaliação do potencial de integração entre o uso e ocupação do solo e o transporte de carga em um recorte urbano de São Paulo. Transportes, 2019. v. 27, n. 2. p.117-135. No prelo. DOI:10.14295/transportes.v27i2.1620

ROUTHIER, J. L.; TOILIER, F. FRETURB V3, A Policy Oriented Software of Modelling Urban Goods Movement. 11th WCTR, jun. 2007, Berkeley, United States of America.

ROUTHIER, J. L.; TOILIER, F. Freturb V3.0 Diagnostic and Simulation Software for Urban Freight Transport. Laboratory of Economy of Transport, University of Lyon, 2013.

SÃO PAULO (Cidade). Lei no 16.050, de 31 de julho de 2014. Política de Desenvolvimento Urbano e o Plano Diretor Estratégico. São Paulo: Diário Oficial da Cidade de São Paulo, 01 de agosto de 2014, ano 59, n. 140, p. 1-352.

SÃO PAULO (Cidade) Secretaria Municipal de Urbanismo e Licenciamento. Dados Estatísticos. Disponível em:

<http://www.prefeitura.sp.gov.br/cidade/secretarias/desenvolvimento_urbano/dados_estati sticos/>. Acesso em: 21 abr. 2019.

SILVA, T. C. M.; MARINS, K. R. C. C. Discutindo o papel do transporte de carga no planejamento urbano: contextualização e comparativo conceitual. In: XXVIII Congresso

Nacional de Pesquisa e Ensino em Transporte da ANPET, 2014, Curitiba, Paraná. 